\title{
Bacteriological Profile and their Antibiotic Susceptibility Pattern in Diabetic Foot Ulcers in a Tertiary Care Hospital, Puducherry, India
}

\author{
K. Manasa Saraswathy ${ }^{1}$, S. Pramodhini ${ }^{1 *}$, C.P. Ganesh Babu ${ }^{2}$, \\ S. Umadevi ${ }^{1}$ and K.S. Seetha ${ }^{1}$ \\ ${ }^{1}$ Department of Microbiology, Mahatma Gandhi Medical College and Research Institute, \\ Puducherry, Sree Balaji Vidyapeeth University, India \\ ${ }^{2}$ Department of General Surgery, Mahatma Gandhi Medical College and Research Institute, \\ Puducherry, Sree Balaji Vidyapeeth University, India \\ *Corresponding author
}

\author{
A B S T R A C T
}

\begin{tabular}{|c|}
\hline Keywords \\
\hline $\begin{array}{l}\text { Diabetic ulcer foot, } \\
\text { Polymicrobial, } \\
\text { Monomicrobial, } \\
\text { Escherichia coli, } \\
\text { Staphylococcus } \\
\text { aureus. }\end{array}$ \\
\hline Article Info \\
\hline $\begin{array}{l}\text { Accepted: } \\
\text { 22 February } 2017 \\
\text { Available Online: } \\
\text { 10 March } 2017\end{array}$ \\
\hline
\end{tabular}

Diabetic foot ulcer is one of the dreaded complications of uncontrolled diabetic mellitus, leading to consequences like gangrene and amputation of foot. This study was conducted as an endeavor to scrutinise the major genera of bacteria which were in association with the infected diabetic foot ulcers and their antibiotic sensitivity pattern. This prospective analytical study included 100 samples from diabetic foot ulcer patients. Isolation and identification of organism were done based on standard laboratory technique. Bacterial susceptibility to antibiotics was determined by Kirby Bauer disc diffusion method. Analysis of 100 samples showed $77 \%$ were culture positive and $23 \%$ were culture negative. Of 77 culture positive 60 (77.9\%) were monomicrobial and $17(22.1 \%)$ were polymicrobial. A total of 97 bacteria were isolated from 77 culture positive samples, of which $67 \%$ were gram negative and $32 \%$ were gram positive bacteria. Antimicrobial sensitivity testing showed that $61.5 \%$ of gram negative bacilli were ESBL producers and $21 \%$ of Staphylococcus aureus was methicillin resistant. In conclusion, the prevalence of MDR organisms, MRSA and ESBL producing organisms are very high in the diabetic foot patients in India because of indiscriminate use of antibiotics which necessitates the need for continuous strict surveillance of resistant bacteria.

\section{Introduction}

Diabetic ulcer foot is one of the dreaded complications of uncontrolled diabetes, leading to severe consequences like gangrene and amputation of foot. The impaired microvascular circulation in diabetic foot patients limits the access of phagocytes, thus favoring the development of an infection. Wearing improper footwear and injuries occurring locally further interfere with the blood supply to lower extremities. Diabetes is the most

common disease in India with a prevalence rate of $12-17 \%$ in the urban and $2.5 \%$ in the rural population (Mohan et al., 2007).

Most probable causative agents of the diabetic foot infections are of polymicrobial etiology, of which most of these bacteria are developing resistance to commonly used antibiotics largely due to their indiscriminate use. Proper management of cases requires 
appropriate selection of antibiotics based on culture and sensitivity report.

This study was conducted as an endeavor to scrutinise the major genera of bacteria which were in association with the infected diabetic foot ulcers and their corresponding antibiotic sensitivity pattern. The bacteriological profile of infected ulcers was compared to that of the previous studies and the changes were observed.

\section{Materials and Methods}

A Prospective Analytical study was conducted in a tertiary care teaching hospital in Pondicherry for duration of 2 months, as Short Term Studentship ICMR project.100 samples from diabetic foot ulcer patients were studied after obtaining the informed written consent. Repeat isolate from the same patients and patients on antibiotic therapy for less than 2 weeks duration will be excluded from the study.

Samples were collected under complete aseptic conditions with a sterile swab from the base of the ulcer and transported immediately to the laboratory without any delay. Samples were inoculated on Blood agar and MacConkey's agar and processed for isolation and identification of organism based on standard laboratory technique (Forbes et al., 1998).

Bacterial susceptibility to antimicrobial agents was determined on Mueller Hinton agar plates by Kirby Bauer disc diffusion method with commercially available discs (Hi-Media, Mumbai).

Isolates based upon interpretive criteria developed by the Clinical and Laboratory Standards Institute was categorized as susceptible, intermediate and resistant strains (CLSI, 2014).

\section{Statistical analysis}

Percentage, mean, standard deviation and $95 \%$ confidence interval were analysed.

\section{Results and Discussion}

In this study, out of 100 diabetic foot ulcers patients, 71 were male and 29 were female with a male: female ratio of 2.4: 1 . The age of the patients ranged from 25 to 80 years. The maximum number of patients $(57 \%)$ was in the age group of 41-60 years. The next most prevalent age group was between 61 and 80 years $(31 \%)$ (Table1).

Of 100 samples studied $77 \%$ were culture positive and $23 \%$ were culture negative. A total of 97 bacteria were isolated from 77 culture positive samples, averaging 1.25 species per patient. In this study, gram negative bacteria $(67 \%)$ were isolated more frequently than gram positive bacteria (32\%). Of 77 culture positive $60(77.9 \%)$ were monomicrobial and 17(22.1\%) were polymicrobial (Table 2).

In the present study, the most common isolate was Escherichia coli (23.71\%), followed by Staphylococcus aureus (19.58\%) and Pseudomonas aeruginosa (15.46\%). The other organisms isolated were Enterococcus spp (12.37\%), Klebsiella spp (11.34\%), Proteus spp (9.27\%) other NFGNB (3.09\%), Acinetobacter spp (2.06\%), Citrobacter spp (2.06\%), Streptococcus pyogenes (1.03\%) (Table 3).

Sensitivity testing of Gram positive organism showed that Staphylococcus aureus which accounted for $19.58 \%$ of isolates were sensitive to most of the $1^{\text {st }}$ line drugs like tetracycline $(78.9 \%)$, erythromycin $(63.1 \%)$, gentamicin and cotrimoxazole (57.8\%), ciprofloxacin $(42.1 \%)$ and $21 \%$ of the isolate was resistant to cefoxitin. The next common 
gram positive isolate Enterococcus spp had highest sensitivity to gentamicin $(58.3 \%)$ and least sensitivity to penicillin and ciprofloxacin
(16.6\%). Streptococcus pyogenes showed $100 \%$ sensitivity to all drugs (Table 4).

Table.1 Age-sex distribution of the diabetic foot ulcer patients

\begin{tabular}{|c|c|c|c|}
\hline Age in years & Female & Male & Total \% \\
\hline $21-40$ & 6 & 6 & $12(12 \%)$ \\
\hline $41-60$ & 15 & 42 & $57(57 \%)$ \\
\hline $61-80$ & 8 & 23 & $31(31 \%)$ \\
\hline Total \% & $\mathbf{2 9}(\mathbf{2 9 \%})$ & $\mathbf{7 1 ( 7 1 \% )}$ & $\mathbf{1 0 0}(\mathbf{1 0 0 \%})$ \\
\hline
\end{tabular}

Table.2 Pattern of isolation of microbial growth and analysis of isolates from diabetic foot ulcer

\begin{tabular}{|c|c|}
\hline Parameters & Number (\%) \\
\hline Total number of patients & 100 \\
\hline Culture positive & $77(77 \%)$ \\
\hline Culture negative & $23(23 \%)$ \\
\hline Total number of isolates & 97 \\
\hline Gram negative bacteria & $65(67 \%)$ \\
\hline Gram positive bacteria & $32(33 \%)$ \\
\hline Monomicrobial & $60(77.9 \%)$ \\
\hline Polymicrobial & $17(22.1 \%)$ \\
\hline
\end{tabular}

Table.3 Bacteria isolated from diabetic foot infections

\begin{tabular}{|c|c|}
\hline Bacteria & No of isolates (\%) \\
\hline Escherichia coli & $23(23.71)$ \\
\hline Staphylococcus aureus & $19(19.58)$ \\
\hline Pseudomonas aeruginosa & $15(15.46)$ \\
\hline Enterococcus spp & $12(12.37)$ \\
\hline Klebsiella spp. & $11(11.34)$ \\
\hline Proteus spp & $9(9.27)$ \\
\hline Other NFGNB & $3(3.09)$ \\
\hline Acinetobacter spp & $2(2.06)$ \\
\hline Citrobacter spp & $2(2.06)$ \\
\hline Streptococcus pyogenes & $1(1.03)$ \\
\hline Total & $\mathbf{9 7 ( 1 0 0 )}$ \\
\hline
\end{tabular}


Table.4 Antimicrobial sensitive (\%) pattern of Gram positive organisms in diabetic foot infections $(\mathrm{n}=32)$

\begin{tabular}{|l|c|c|c|}
\hline \multirow{2}{*}{ Antibiotic } & $\begin{array}{c}\text { Staphylococcus } \\
\text { aureus }(\mathbf{n}=\mathbf{1 9})\end{array}$ & $\begin{array}{c}\text { Streptococcus } \\
\text { pyogens }(\mathbf{n = 1})\end{array}$ & $\begin{array}{c}\text { Enterococcus spp } \\
(\mathbf{n = 1 2})\end{array}$ \\
\cline { 2 - 4 } & $\mathbf{S ( \% )}$ & $\mathbf{S}(\%)$ & $\mathbf{S}(\%)$ \\
\hline Penicillin & $2(10.5)$ & $1(100)$ & $2(16.6)$ \\
\hline Erythromycin & $12(63.1)$ & $1(100)$ & $5(41.7)$ \\
\hline Cotrimoxazole & $11(57.8)$ & $1(100)$ & - \\
\hline Gentamicin & $11(57.8)$ & $1(100)$ & $2(16.6)$ \\
\hline Ciprofloxacin & $8(42.1)$ & $1(100)$ & $4(33.3)$ \\
\hline Tetracycline & $15(78.9)$ & $1(100)$ & - \\
\hline Cefoxitin & $15(78.9)$ & $1(100)$ & \\
\hline S= Sensitive &
\end{tabular}

$\mathrm{S}=$ Sensitive $\quad \mathrm{R}=$ Resistant

Table.5 Antimicrobial sensitivity (\%) pattern of Gram negative organisms in diabetic foot infections $(\mathrm{n}=45)$

\begin{tabular}{|l|c|c|c|c|c|c|c|}
\hline \multirow{4}{*}{ Antibiotic } & \multicolumn{3}{|c|}{ Enterobacteriaceae(n=45) } & \multicolumn{3}{c|}{$\begin{array}{c}\text { Non fermenting Gram } \\
\text { Negative bacilli(n=20) }\end{array}$} \\
\cline { 2 - 8 } & $\begin{array}{c}\text { Escheric } \\
\text { hia coli } \\
(\mathbf{n = 2 3 )}\end{array}$ & $\begin{array}{c}\text { Klebsiella } \\
\text { spp } \\
(\mathbf{n = 1 2})\end{array}$ & $\begin{array}{c}\text { Proteus } \\
\text { spp } \\
(\mathbf{n = 9})\end{array}$ & $\begin{array}{c}\text { Citroba } \\
\text { cterspp } \\
(\mathbf{n = 1})\end{array}$ & $\begin{array}{c}\text { Pseudom } \\
\text { onas spp } \\
(\mathbf{n = 1 5})\end{array}$ & $\begin{array}{c}\text { Acineto } \\
\text { bacter } \\
(\mathbf{n = 2})\end{array}$ & $\begin{array}{c}\text { other } \\
\text { NFGNB } \\
(\mathbf{n = 3})\end{array}$ \\
\cline { 2 - 8 } $\mathbf{S ( \% )}$ & $\mathbf{S ( \% )}$ & $\mathbf{S ( \% )}$ & $\mathbf{S}(\%)$ & - & - & - \\
\hline Ampicillin & $5(21.7)$ & - & $2(22.2)$ & 0 & - & - & - \\
\hline Cotrimoxazole & $7(30.4)$ & $7(58.3)$ & $2(22.2)$ & 0 & - & - & - \\
\hline Amikacin & $18(78.3)$ & $8(66.7)$ & $6(66.7)$ & 0 & $10(66.6)$ & $1(50)$ & 0 \\
\hline Gentamicin & $11(47.8)$ & $2(16.7)$ & $3(33.3)$ & 0 & $6(40)$ & 0 & $1(33.3)$ \\
\hline Tobramycin & - & - & - & & $8(53.3)$ & $1(50)$ & 0 \\
\hline Ciprofloxacin & $5(21.7)$ & $5(41.7)$ & $4(44.4)$ & 0 & $10(66.6)$ & 0 & 0 \\
\hline Ceftriaxone/Ceftazidime & $5(21.7)$ & $4(33.3)$ & $5(55.6)$ & 0 & $10(66.6)$ & 0 & $1(33.3)$ \\
\hline Imipenem & $22(95.7)$ & $12(100)$ & $9(100)$ & $1(100)$ & $13(86.7)$ & $1(50)$ & $2(66.6)$ \\
\hline PiperacillinTazobactum & $18(78.3)$ & $10(83.3)$ & $7(77.8)$ & $1(100)$ & $14(93.3)$ & 0 & $1(33.3)$ \\
\hline
\end{tabular}

The predominant isolate Escherichia coli $(23.7 \%)$ showed maximum sensitivity to Imipenem $(95.7 \%)$, followed by piperacillin tazobactum and amikacin (78.3\%), Gentamicin (47.8\%) and Cotrimoxazole $(30.4 \%)$. Other enterobacteriaceae like
Klebsiella spp, Proteus spp and Citrobacter spp were $100 \%$ sensitive to Imipenem. Study on antimicrobial susceptibility pattern of non fermenting gram negative bacilli in diabetic foot infections showed that Pseudomonas aeruginosa being the $3^{\text {rd }}$ highest isolate 
(15.4\%) was $93.3 \%$ sensitive to piperacillin tazobactum, followed by imipenem, $(86.7 \%)$ and $66.6 \%$ sensitivity to ceftazidime, ciprofloxacin and amikacin (Table 5).

Diabetic foot ulcers are one of the major public health problems leading to socioeconomic burden to the suffering individuals. This study comprehends the microbiological profile of infected diabetic foot ulcers in hospitalized patients. As higher resistance is a growing problem, effort was made to study the sensitivity and resistance pattern of bacteria isolated from diabetic ulcer foot.

In this study, out of 100 diabetic foot ulcers patients, 71 were male and 29 were female with a male: female ratio of 2.4: 1 . Increased male prevalence has been reported in other studies as comparable to our study (Bansal et al., 2008; Sekhar et al., 2014; Gadepalli et al., 2006).

In the current study, predominant number of patients (57\%) was in the age group of 41-60 years. Well correlating with similar other studies (Bansal et al., 2008; Hena et al., 2010).

Bansal et al., 2008 in their study stated that, most commonly, the causative agents of diabetic foot infections are of polymicrobial in nature. The polymicrobial etiology of most diabetic foot ulcers is possibly one of the major contributing factors for the chronicity of diabetic foot ulcers. Among 100 cases, $77 \%$ had microbial growth and $23 \%$ were sterile. This is in accordance with the results of study conducted in North India, which showed $21 \%$ no growth. This is may be due to the use of inappropriate systemic or topical antibiotics, as an initial treatment.

In the current study, we observed 60(77.9\%) mono-microbial infection and 17(22.1\%) poly-microbial infection. In our study, we observed predominance of monomicrobial infection, in concordance with various other studies (CLSI, 2014; Tiwari et al., 2012; Dhanasekaran et al., 2003).

Candel et al., 2003, have observed that microbial etiology of diabetic foot ulcers were due to a variety of aerobic bacteria (Staphylococcus spp., Streptococcus spp. and Enterobacteriaceae), anaerobic flora (Bacteroides spp., Clostridium spp. and Peptostreptococcus spp.) and fungi .Microbiological evaluation of diabetic foot ulcer infections in several Indian studies showed the preponderance of Gram negative organisms, to be more than Gram-positive organisms (Tiwari et al., 2012; Richard et al., 2011).

Out of 97 bacteria isolated from 77 culture positive cases, $67 \%$ were Gram negative and $33 \%$ were Gram-positive bacteria. This is in line with the report of previous other studies (Tiwari et al., 2012; Shankar et al., 2005).

In our study the predominant isolate was Escherichia coli (23.71\%) followed by Staphylococcus aureus (19.58\%), and Pseudomonas aeruginosa (15.46\%).These findings correlated with the various other studies conducted (Tiwari et al., 2012; Swarna et al., 2012; Esmat et al., 2012).

Knowledge on the antibiotic susceptibility pattern of the bacteria isolated from diabetic foot infections is very crucial for planning the appropriate treatment of these cases, prior to getting the susceptibility reports from the laboratory. More recently, an increase in the incidence rate of multi-drug resistant (MDR) organisms, namely Methicillin Resistant Staphylococcus aureus (MRSA) and Extended-Spectrum Beta Lactamase (ESBL)producing gram-negative bacteria, has become challenging and threatening the final 
outcome of anti-infectious therapy in the community as well as in hospitalized patients (Tascini et al., 2011). Initial antimicrobial treatment of severe or life threatening infections involves the use of broad spectrum antibiotics, aimed at its polymicrobial etiology. Escherichia coli were the most predominant isolate and it showed maximum sensitivity to Imipenem (95.7\%), followed by amikacin $(78.3 \%)$, gentamicin $(47.8 \%)$ and cotrimoxazole (30.4\%). However, Bansal et al., 2008, reported sensitivity to Imipenem 100\%, Amikacin 90\%, Gentamicin 30\%, cotrimoxazole $33.3 \%$. The sensitivity pattern of Imipenem and cotrimoxazole is in accordance with our study, whereas that of Amikacin is higher than our study (Bansal et al., 2008). Hena et al., 2010, reported the sensitivity pattern of Imipenem to be $94.1 \%$ which correlates with the present study.

The emergence of plasmid-mediated ESBLs among members of Enterobacteriaceae has increased worldwide. In our study, $68.8 \%$ of Enterobacteriaceae were ESBL producers. Recent studies from India have reported prevalence of ESBL producers to be as high as $68 \%$, similar to our study (Mathur et al., 2002).

Methicillin resistant staphylococcal infections are the most common hospital acquired infections which require higher antibiotics for treatment. The rising incidence of MRSA, requires early culture attempts and close surveillance of patients initially treated with Beta-lactam agents.

Staphylococcus aureus being the next predominant isolate, showed maximum sensitivity to cefoxitin ( $78.9 \%)$, followed by tetracycline $(78.9 \%)$, and erythromycin $(63.1 \%)$, this is corresponding to the sensitivity pattern of Staphylococcus aureus conducted by Bansal et al., 2008. In India incidence of MRSA shows variation from
$6.9 \%$ to $81 \%$ (Verma et al., 2000). In our study, we observed, $21 \%$ of Staphylococcus aureus isolates were resistant to Methicillin, which is in accordance with the results of the study conducted by Yates et al., 2009.

In this study, Pseudomonas aeruginosa were highly sensitive to piperacillin tazobactam $(93.3 \%)$, followed by imipenem, $(86.7 \%)$ and ceftazidime (66.6\%), amikacin (66.6\%), ciprofloxacin $(66.6 \%)$. Sensitivity pattern on Pseudomonas correlated with the other studies (Bansal et al., 2008; Sekhar et al., 2014).

In conclusion, the prevalence of Multi Drug Resistance organisms (MDR), MRSAs and ESBL producing organisms are very high in the diabetic foot patients in India because of indiscriminate use of antibiotics. Thus there is an alarming need for continuous strict surveillance of resistant bacteria, for appropriate selection of antibiotics based on culture and sensitivity report so that there will be proper management of diabetic foot ulcers without any complications.

\section{Acknowledgement}

We would like to thank the ICMR for sponsoring this Short Term Studentship (STS) project.

\section{References}

Bansal, E., Garg, A., Bhatia, S., Attri, A.K., Chander, J. 2008. Spectrum of microbial flora in diabetic foot ulcers. Indian $J$. Pathol. Microbiol., 51: 204.

Candel Gonzalez, F.J., Alramadan, M., Matesanz, M., Diaz, A., Gonzalez-Romo, F., Candel, I., et al. 2003. Infections in diabetic foot ulcers. Eur. J. Int. Med., 14: 341-343.

Clinical and Laboratory Standards Institute. 2014. Performance Standards for Antimicrobial Susceptibility testing, 
twenty fourth informational supplement, M100-S24, Clinical and Laboratory Standards Institute.

Dhanasekaran, G., Sastry, G., Viswanathan, M. 2003. Microbial pattern of soft tissue infections in diabetic patients in South India. Asian J. Diabet., 5: 8-10.

Esmat, M.M., Saif Al Islam, A. 2012. Diabetic foot infection: Bacteriological causes and antimicrobial therapy. J. Am. Sci., 8(10): 389-393.

Forbes, B.A., Sham, D.F., Weissfeld, A.S., editors. 1998. Overview of Conventional methods for bacterial identification. Chapter 13. In: Baliley and Scott's Diagnostic Microbiology, 10th ed. St. Louis: The 'CV Mosby Company.

Gadepalli, R., Dhawan, B., Sreenivas, V., Kapil, A., Ammini, A.C., Chaudhry, R. 2006. A clinico- microbiological study of diabetic foot ulcers in an Indian tertiary care hospital. Diabetes Care, 29: 1727-1732.

Hena, J.V., Growther, L. 2010. Studies on Bacterial Infections of Diabetic Foot Ulcer. Afr. J. Cln. Exper. Microbiol., 11(3): 146-149.

Mathur, P., Tatman, A., Das, B., Dhavan, B. 2002. Prevalence of ESBL gram negative bacteria in a tertiary care hospital. Indian J. Med. Microbiol., 115: 153-157.

Mohan, V., Sandeep, S., Deepa, R., Shah, B., Varghese, C. 2007. Epidemiology of type 2 Diabetes: Indian Scenario. Indian J. Med. Res., 125: 217-230.

Richard, J.L., Sotto, A., Lavigne, J.P. 2011. New insights in diabetic foot infection. World J. Diabetes, 2: 24-32.
Sekhar, S.M., Vyas, N., Unnikrishnan, M.K. Antimicrobial susceptibility pattern in diabetic foot ulcers, Annals of Med. Health Sci. Res., 4(5): 742-745.

Shankar, E.M., Mohan, V., Premalatha, G., Srinivasan, R.S., Usha, A.R. 2005. Bacterial etiology of diabetic foot infections in South India. Eur. J. Int. Med., 16: 567-570.

Swarna, S.R., Madhavan, R., Gomathi, S., Devaraj, Thamaraiselvi, S. 2012. A study of Biofilm on Diabetic Foot Ulcer, Int. J. Res. Pharmaceutical and Biomed. Sci., 3(4): 1809-1814.

Tascini, C., Piaggesi, A., Tagliaferri, E., Iacopi, E., Fondelli, S., Tedeschi, A., et al. 2011. Microbiology at first visit of moderate-to severe diabetic foot infection with antimicrobial activity and a survey of quinolone monotherapy, Diabetes Res. Clin. Practice.

Tiwari, S., Pratyush, D.D., Dwivedi, A., Gupta, S.K., Rai, M., Singh, S.K. 2012. Microbiological and clinical characteristics of diabetic foot infections in northern India. J. Infect. Dev. Ctries., 6(4): 329-332.

Verma, S., Joshi, S., Chitnis, V., Hemwani, N., Chitnis, D. 2000. Growing problem of methicillin resistant StaphylococciIndian scenario. Ind. J. Med. Sci., 54(12): 535-540.

Yates, C., May, K., Hale, T., Bernard Allard, Naomi Rowings, Am Freeman, et al. 2009. Wound Chronicity, Inpatient care \& Chronic Kidney Disease Predispose to MRSA Infection in Diabetic Foot Ulcers. Diabetic Care, 32: 1907-1909.

\section{How to cite this article:}

Manasa Saraswathy, K., S. Pramodhini, C.P. Ganesh Babu, S. Umadevi and Seetha, K.S. 2017. Bacteriological profile and their antibiotic susceptibility pattern in diabetic foot ulcers in a tertiary care hospital, Puducherry. Int.J.Curr.Microbiol.App.Sci. 6(3): 1560-1566. doi: https://doi.org/10.20546/ijcmas.2017.603.179 